San Jose State University

From the SelectedWorks of Marjorie R. Freedman

2010

\title{
Obesity and Food Choices Among Faculty and Staff at a Large Urban University
}

Marjorie R. Freedman, San Jose State University

Rebecca J. Rubinstein, San Jose State University 


\section{Obesity and Food Choices Among Faculty and Staff at a Large Urban University Journal of American College Health 2010; 59, 205-210 Marjorie R. Freedman and Rebecca J. Rubinstein}

Abstract. Objective: In order to address increasing health care costs associated with obesity, this study sought to determine prevalence of overweight and obesity [high body mass index (BMI)], and examine eating behaviors, food choices, health beliefs and attitudes of university employees. Participants and Methods: An on-line survey was distributed to $>3,800$ faculty and staff at a large public metropolitan university in Winter 2008. Results: Almost half (48\%) of 806 respondents had a high BMI. Compared to normal weight respondents, high BMI respondents consumed fewer fruits and vegetables $(p<.05)$, were less confident in making healthful food choices $(p<.001)$, and were more influenced by food choices available in oncampus dining facilities $(p<.05)$. Conclusions: Obesity among university employees warrants attention. Since these employees have less self-efficacy and consume less healthful diets than their normal weight colleagues, universities need to improve on-campus access to healthful foods.

Keywords: Faculty and staff, food choices, obesity, university

The prevalence of overweight and obesity [body mass index $(\mathrm{BMI}) \geq 25$ ] has increased dramatically over the past decades. ${ }^{1}$ Obesity increases the risk of chronic disease, including cardiovascular disease, type 2 diabetes, certain forms of cancer, depression, and many other physical and social comorbidities. ${ }^{2}$ These diseases, in turn, reduce workforce productivity and increase employer health care costs. ${ }^{3}$ The annual medical cost of obesity was approximately $\$ 78$ billion in 1998 , but rose to $\$ 147$ billion by $2008 .{ }^{4}$ Annual medical expenses are estimated to be $21 \%$ higher for overweight and obese employees. ${ }^{5}$ These tremendous costs, coupled with poor treatment outcomes, call for public health strategies focusing on obesity prevention.

The Task Force on Community Preventive Services has proposed public health strategies for preventing and controlling overweight and obesity in worksite settings. ${ }^{6}$ Because $65 \%$ of the

30 population $\geq 16$ years of age is in the workforce, ${ }^{7}$ the worksite is a natural place to implement obesity preventive strategies that modify the food environment and/or increase opportunities for physical activity. ${ }^{8}$ The worksite affords opportunities to modify food choices through social and environmental supports, and through policies that promote healthful eating. Social supports include peer and organizational norms, while environmental supports include improved access to

35 healthful foods and decreased proliferation of unhealthful foods. ${ }^{9}$ Worksite policies designed to make healthful choices easier, such as increasing healthful foods served at meetings and in vending machines, ${ }_{11}^{10}$ are likely to be sustained for a longer period of time than are individually oriented strategies. ${ }^{11}$

Worksite obesity prevention programs have taken place in various settings, including 40 large corporate settings, manufacturing sites, hospitals, hotels and schools. ${ }^{6,9,12-16}$ Most studies have combined behavioral and education strategies to influence diet and physical activity. There is limited information on how the work environment can be modified to effect measurable changes in body weight. In addition, few studies have focused on worksite wellness programs in a university setting, ${ }^{17}, 18$ despite a recent call to action on the health and wellness of university 45 students, faculty and staff. ${ }^{19}$

Throughout the US, there are over 4,300 institutions of higher education employing over 
3.5 million faculty and staff. ${ }^{20}$ Universities are important environments for developing strategies and policies to address health care issues as they comprise diverse age, racial, and socioeconomic populations, and they face enormous cost pressures and incentives to maintain a healthy workforce. Universities also have the resources to support multi-component interventions at all levels: individual, interpersonal, community and environment. Further, the university setting provides a unique environment for interaction and influence between and among faculty, staff and students.

Unfortunately, little is known about the health status of the university employee

55 population, including their rates of overweight and obesity, usual dietary intake, and eating habits. Consequently, the primary objective of this formative research was to address these gaps in knowledge by conducting a study on a large, urban university that employs about 3,900 full and part-time faculty and staff. A secondary objective was to provide data to inform policy changes relating to food access and availability on this campus. The socio-ecological model was used to inform this research, as this model provides a framework to describe individual change within a context of social change, and it recognizes both that an individual's behavior is affected by their physical, economic, policy, and socio-cultural environments, ${ }^{21}$ and that individuals make significant health decisions within these complex environments. ${ }^{22}$

\section{METHODS}

\section{Subject Recruitment}

The Institutional Review Board for human subjects at a large urban university approved this research. All full and part-time faculty and staff $(\mathrm{N}=3,890)$ with email addresses provided by the university human resources department were eligible to participate in this on-line survey (www.SurveyMonkey.com, Portland, OR). Participants provided informed consent prior to survey access. During February 2008, all employees were contacted via SurveyMonkey's email messaging system; 3 follow-up emails were sent over the next month. Participants who completed surveys were entered into a drawing for one of four $\$ 25.00$ gift cards.

\section{Survey Design and Measures}

A quantitative, cross-sectional 40-question survey designed specifically for this study was pre-tested, prior to being fielded, by university employees excluded from participation. The survey collected demographic data on gender, university affiliation, number of days on campus, and length of employment. Self-reported weight and height were used to calculate BMI [(weight in pounds $\mathrm{x} .703) /\left(\right.$ height in inches $\left.\left.{ }^{2}\right)\right]$. BMI was used as a categorical variable, based on the Centers for Disease Control and Prevention's classification of underweight, normal weight, overweight and obese. ${ }^{23}$ Dietary habits, food purchase behaviors, and influences on eating behaviors were also assessed. Since intake of fruit and vegetables have been associated with changes in body weight, ${ }^{24}$ total intake of these foods was separately measured, based on selfreported estimates of typical daily consumption using survey-provided specified USDA portion size definitions. ${ }^{25}$ Daily consumption of dairy products and grains were also assessed.

Measures of the physical nutrition environment were based on respondents' perceived access to food. Respondents were asked a series of 5-point Likert scale questions on food access and availability (e.g., "How satisfied are you with the availability of fruits and vegetables on 
campus?", and "How satisfied are you with the availability of dining options on campus?") where $1=$ not at all satisfied; $2=$ somewhat satisfied; $3=$ neutral; $4=$ satisfied; and $5=$ very

95 satisfied. Respondents were also asked whether they would purchase food on campus more frequently if there were more places to buy food. The influence of family, friends and coworkers on food choices (social norms) (e.g., "The food my friends eat influences what I eat") and respondents' perceived personal attitudes about health and nutrition (e.g.,"Maintaining my health is important to me," and "What I eat affects my health") were also assessed with 5- point

100 Likert scale questions $(1=$ strongly disagree; $2=$ somewhat disagree; $3=$ neutral; $4=$ somewhat agree; $5=$ strongly agree). At the end of the survey, respondents were given an open-ended prompt, "Is there anything else you would like to tell us about food options or eateries on campus?"

\section{Data Analysis}

SPSS for Macintosh Version 16.0 (SPSS, Inc., Chicago, IL 2008) was used to analyze data. Frequencies determined food group intake and where and how often food was purchased. Pearson's chi-square tests analyzed the association between ethnicity, gender, affiliation, food intake, beliefs and attitudes about health and food choices, and BMI category (normal weight, overweight and obese), after elimination of the small number of respondents in the underweight category. One-way ANOVA examined the relationship between BMI category and age, days on campus, and years employed. The relationship between BMI and total intake of fruits and vegetables was assessed using Pearson's correlation. Statistical significance was set at $p<.05$.

\section{RESULTS}

Of the 3,890 employees sent emails, 180 had undeliverable addresses, and 16 employees opted out. Of the balance, 954 employees answered at least $90 \%$ of survey questions (a $26 \%$

120 response rate). However, 30 respondents were excluded because they worked exclusively from home, and 118 respondents failed to provide height and weight data. Demographic characteristics of the final sample $(\mathrm{N}=806)$ are shown in Table 1. The distribution of respondents' affiliation and ethnicity matches that for all university employees.

The mean BMI of respondents, as calculated from self-reported height and weight, was

$12525.9+5.3$ (range $16.2-51.7$ ). Thus, $48 \%$ of respondents were classified as being overweight or obese $(\mathrm{BMI} \geq 25)$. BMI was significantly related to gender $(p<.05)$, ethnicity $(p<.001)$, and age $(p<.05)$. More men $(60 \%)$ compared to women $(43 \%)$ had BMIs $\geq 25$. Hispanic employees comprised the highest percentage $(61 \%)$ of overweight and obese respondents, followed by African American (59\%), Filipino (54\%), white (50\%) and Asian (29\%). BMI was

130 higher in older respondents, but it was not related to affiliation (e.g., faculty, staff or administrative status), number of days on campus (e.g. full- or part-time status), or years of employment. 
TABLE 1. Respondents' Demographic Characteristics $(\mathrm{N}=\mathbf{8 0 6})$

\begin{tabular}{|c|c|c|}
\hline Variable & Value & \\
\hline Age in years (range) & $44.8 \pm 11.9(20-85)$ & \\
\hline Years employed at this university (range) & $9.0 \pm 9.0(1-58)$ & \\
\hline University Affiliation & $\%$ & $\mathrm{n}$ \\
\hline Full-time faculty & 20.7 & 167 \\
\hline Full-time staff & 41.8 & 337 \\
\hline Part-time faculty & 20.3 & 164 \\
\hline Part-time staff & 5.4 & 44 \\
\hline Administration & 11.6 & 94 \\
\hline Gender & $\%$ & $\mathrm{n}$ \\
\hline Male & 29 & 233 \\
\hline Female & 71 & 573 \\
\hline Ethnicity & $\%$ & $\mathrm{n}$ \\
\hline African American & 3.8 & 29 \\
\hline Asian & 14.5 & 111 \\
\hline Filipino & 3.1 & 24 \\
\hline Hispanic & 12.6 & 96 \\
\hline White & 65.9 & 503 \\
\hline BMI category & $\%$ & $\mathrm{n}$ \\
\hline Underweight $(\mathrm{BMI}<18.5)$ & 1.4 & 11 \\
\hline Normal weight (BMI 18.5 - 24.99) & 50.6 & 408 \\
\hline Overweight (BMI 25 - 29.99) & 28.5 & 230 \\
\hline Obese $(\mathrm{BMI} \geq 30)$ & 19.5 & 157 \\
\hline Days on campus each week & $\%$ & $\mathrm{n}$ \\
\hline One & 5.0 & 40 \\
\hline Two & 11.7 & 94 \\
\hline Three & 9.0 & 73 \\
\hline Four & 12.5 & 101 \\
\hline Five & 61.8 & 498 \\
\hline
\end{tabular}

\section{Food Group Intake and Body Mass Index}

Fifty-one percent $(n=411)$ of respondents consumed the recommended 5 servings of

140 fruit and vegetables/day. Mean daily fruit and vegetable intake for normal weight employees was significantly greater than that of overweight and obese employees $(5.2 \pm 2.3,4.7 \pm 2.1$, and $4.4 \pm 2.1$, respectively) $(p<.05)$. There was a weak negative correlation between BMI and total daily fruit and vegetable intake $(\mathrm{r}=-.101 ; p<.01)$.

Only $8 \%(n=61)$ of respondents consumed the recommended 6 servings/day of grains.

145 Mean daily intake was $3.1 \pm 1.4$ servings. Seventy-nine percent $(n=638)$ of respondents failed to consume the recommended 3 servings/day of dairy products (mean intake was $1.7 \pm 1.0$ servings/day). There were no significant differences between normal, overweight, or obese respondents in daily intake of grains or dairy products. 
More than $80 \%$ of respondents $(n=662)$ reported they did not consume non-diet sodas

150 or energy drinks. There was no significant difference in consumption of these beverages among BMI groups (normal weight, overweight, and obese respondents consumed 0.2, 0.3 and 0.4 servings/day, respectively).

\section{Campus Food Purchases and Attitudes about Campus Food Choices}

Of the 806 respondents, $541(62 \%, \mathrm{n}=498)$ reported being on campus 5 days/week and $672(83 \%)$ reported at least 3 days/week. Of the employees on campus 5 days/week, $5 \%(n=23)$ purchased lunch on campus daily while $21 \%(\mathrm{n}=102)$ purchased lunch at least 3 days/week. While a majority of respondents $(60 \%, \mathrm{n}=469)$ purchased lunch on campus at least 1 day/week

160 (irrespective of number of days on campus), only $6 \%(n=47)$ purchased lunch on campus every day that they were on campus, whereas $72 \%(n=570)$ brought lunch from home at least once a week. Twenty-eight percent $(n=229)$ ate at off-campus restaurants at least once a week. Few employees ate breakfast or dinner on campus. Of the $23 \%$ of respondents $(n=179)$ who purchased breakfast on campus at least once a week, just over half $(n=84)$ purchased breakfast

165 only once a week. Dinner was consumed on campus at least once a week by $14 \%(\mathrm{n}=107)$ of respondents. Almost all employees $(88 \%, n=707)$ ate snacks daily; $41 \%(n=331)$ purchased snacks from on-campus eateries at least 1 day/week, while $40 \%(n=319)$ snacked on food provided by their department, another $19 \%(\mathrm{n}=151)$ purchased snacks from vending machines, and $77 \%(\mathrm{n}=620)$ ate snacks brought from home.

$170 \quad$ Forty-two percent of respondents were not satisfied with food choices on campus. Only $13 \%$ were satisfied with the availability of fruits and vegetables on campus, and only $11 \%$ were satisfied with the number of places to eat on campus. When asked what would induce them to purchase food more frequently on campus, the top 3 responses were "there were different food choices (e.g., more vegetarian, low-fat, ethnic foods)" (71\%), "an on-campus Farmers' market"

175 (58\%), and "more places to purchase food on-campus" (53\%). Eating on campus more frequently had little to do with an employee's schedule.

\section{Beliefs and Attitudes about Health and Individual Food Choices}

180 Of all respondents, $80 \%$ agreed or strongly agreed that they were in good health. Significantly more normal weight and overweight, compared to obese respondents, perceived themselves to be in good health $(p<.001)$, and $73 \%$ of all employees strongly agreed that it is important to maintain their health, although significantly fewer obese respondents provided this response $(p<.05)$. Seventy-six percent of respondents strongly believed that what they eat

185 affects their health, and 69\% strongly agreed that what they weigh affects their health. There were no differences in these responses based on BMI categories.

Obese employees, compared to normal and overweight, were significantly less confident in their ability to make healthful food choices $(p<0.001)$. Overweight and obese, as compared to normal weight employees, were significantly more influenced by their friends' and

190 colleagues' food choices ( $p<.01, p<.001$, respectively), but were not more influenced by the foods their spouse or children ate. Employees with high BMIs were more influenced by food available on campus and surrounding neighborhoods $(p<.05)$. 
Over 250 respondents $(31 \%)$ provided qualitative feedback to the open-ended question at the end of the survey, and comments were collated into categories. The 4 categories that received the most comments were those related to food choices/offerings, faculty/staff dining options, 200 dining hours of operation, and dining locations.

Written comments supported the survey's quantitative results, thereby indicating that employees wanted healthier food choices and more options. Some respondents expressed concern with the quality of current food options, e.g., "I am appalled at all the soft drinks and unhealthy snacks available ... I envision a salad bar where the ingredients are all wholesome 205 and natural." Another employee responded, "Most of the food options are too high in fat and calories." Other respondents wanted more variety, e.g., "The variety is lacking," and "I would like to see more variety, more 'home-cooked' healthy options."

Several responses supported the quantitative finding that employees would purchase food more frequently if there were convenient access to better food choices. "My job is so consuming

210 that access to healthful food needs to be quick and convenient." "Food options on campus are extremely limited. I would buy food on campus more if there were more healthy and diverse options." "Both students and faculty need healthier options. There appears to be the same old highly processed, nutritionally-lacking junk. There may be other options, but not very visible ones."

\section{COMMENT}

This research found that $48 \%$ of employees on a large metropolitan campus were classified as overweight or obese, and that obesity rates were highest in Hispanic and African

220 American employees. Although prevalence of overweight and obesity on this campus is lower than the $68 \%$ currently reported for the US adult population, ${ }^{26}$ that rate is still high and warrants attention.

Overweight and obese employees reported eating fewer fruits and vegetables than their normal weight peers. BMI was significantly, albeit weakly, correlated with total fruit and

225 vegetable intake. This finding is important, since diets high in fruits and vegetables may protect against weight gain. ${ }^{24}$ Universities have an opportunity to increase access to fruits and vegetables (and to positively affect food choices) through existing food venues on campus, as well as through the establishment of a Farmers' market or a Community Supported Agriculture (CSA) program. ${ }^{27}$

230 A surprising finding of this study was that even though most university employees had some experience with dining options on campus, the majority did not eat on campus on a regular basis. Only $5 \%$ of full-time employees purchased lunch on campus daily. The attitudes and beliefs about the campus food environment indicate that employees' perceptions of current food offerings on this campus directly impact whether employees eat on or off campus or bring food

235 from home. The data further suggest that employees care about eating healthfully, but do not perceive that the university does an adequate job of providing healthful food choices. In addition, the current research indicates that overweight and obese employees are less confident in their ability to make healthful food choices, and are more influenced by food choices in the dining facilities, their peers and their friends.

240 Together, the above findings suggest 3 important opportunities to encourage healthful 
eating and support wellness of university employees: 1) increase the availability and access to healthful foods in all on-campus eating venues; ${ }^{9}$ 2) increase awareness of healthful options in these establishments via marketing and promotion; ${ }^{28}$ and 3 ) provide point-of-purchase nutrition information in campus dining venues to assist employees to identify more healthful options. ${ }^{29,30}$

245 This study's findings also point out the need for universities to sponsor wellness programs that increase employee self-efficacy to make healthful food choices, and to adopt policies that increase availability and access to healthful foods on-campus. These changes, individually and especially in tandem, are likely to encourage more employees to eat on campus and to consume more healthful foods.

250 This study's main limitation is its reliance on self-reported measures of body weight, food consumption and purchasing behaviors. Those with an interest in the topic may have been more likely to respond to the survey, creating bias. Finally, this study's findings may have limited applicability to universities with different physical, socio-cultural, economic and policy environments, and may not be representative of university faculty and staff at other institutions.

\section{Conclusion}

This study is the first to characterize BMI, food intake patterns, food-purchasing behaviors, and health beliefs and attitudes among university employees. This study's findings

260 provide needed insights into the multifarious factors that influence food choices, and these findings support recommended strategies to effectively combat overweight and obesity in a university setting. At a minimum, this study's findings strongly counsel for increased access to fruits and vegetables on campus. It is thus hoped that universities will offer a wide variety of culturally acceptable healthful choices in the campus-dining environment to assist overweight 265 and obese employees (already suffering from lower self-efficacy) to eat healthier meals and snacks. In sum, universities should enact policies that support health and wellness among all persons who attend or work at these institutions.

\section{ACKNOWLEDGEMENTS}

270 This research was supported by grant from Kaiser Permanente.

\section{REFERENCES}

1. Ogden CL, Carroll MD, Curtin LR, et al. Prevalence of overweight and obesity in the United States, 1999-2004. JAMA. 2006;295:1549-1555.

2. US Department of Health and Human Services. National Institutes of Health. Clinical Guidelines on the Identification, Evaluation, and Treatment of Overweight and Obesity in Adults. http://www.nhlbi.nih.gov/guidelines/obesity/practgde.htm. Accessed January 5, 2010.

280 3. US Department of Health and Human Services. Prevention Makes Common Cents. http://aspe.hhs.gov/health/prevention/\#N_43_. Accessed January 5, 2010.

4. Finkelstein EA, Trogdon, JG, Cohen, JW, Dietz, W. Annual medical spending attributable to obesity: payer-and service-specific estimates. Health Aff (Millwood). 2009; 28:w822-w831. doi: 10.1377/hltaff.28.5.w822. 
285 5. Wilson MG, Goetzel RZ, Ozminkowski RJ, et al. Using formative research to develop environmental and ecological interventions to address overweight and obesity. Obesity. 2007; 15 (suppl 1):S37-47.

6. Katz DL, O'Connell M, Yeh MC, et al. Public health strategies for preventing and controlling overweight and obesity in school and worksite settings: a report on recommendations of the

290 Task Force on Community Preventive Services. MMWR 2005; Rep 54 (RR-10):1-12.

7. Clark SL, Iceland J, Palumbo T, Posey K, Weismantle M. Comparing employment, income, and poverty: Census 2000 and the current population survey. http://www.census.gov/hhes/www/laborfor/final2 b8 nov6.pdf. Accessed October 12, 2009.

8. Centers for Disease Control and Prevention. CDC's LEAN Works! - A Workplace Obesity Prevention Program. http://www.cdc.gov/leanworks/build/healtheductation.html. Accessed February 1, 2010.

9. Engbers L, van Poppel MNM, Chin MJ, van Mechelen W. Worksite health promotion programs with environmental changes, a systematic review. Am J Prev Med. 2005;29:61-70.

10. California Department of Public Health. Worksite Program California Fit Business Kit! http://www.cdph.ca.gov/PROGRAMS/CPNS/Pages/WorksiteFitBusinessKit.aspx. Accessed January 10, 2010.

11. Task Force on Community Preventive Services. Recommendations to increase physical activity in communities. Am J Prev Med. 2002;22(suppl 4):67-72.

12. Anderson LM, Quinn, TA, Glanz K, et al. The effectiveness of worksite nutrition and physical activity interventions for controlling employee overweight and obesity. A Systematic Review. Am J Prev Med. 2009;37:340-357.

13. Beresford SA, Thompson B, Feng Z, Christianson A, McLerran D, Patrick D. Seattle 5 a Day worksite program to increase fruit and vegetable consumption. Prev Med. 2001;32:230238.

310 14. Sorenson G, Stoddard A, Hunt MK, et al. The effects of a health promotion-health protection intervention on behavior change: the WellWorks study. Am J Public Health. 1998;88:1685-1690.

15. Webber LS, Johnson, CC, Rose D, Rice JC. Development of Action! Wellness program for elementary school personnel. Obesity. 2007;15(suppl 1):48S-56S.

315 16. Williams AE, Vogt TM, Stevens VJ, et al. Work, weight, and wellness: the $3 \mathrm{~W}$ Program: a worksite obesity prevention and intervention trial. Obesity. 2007;15(suppl 1):16S-26S.

17. Haines DJ, Davis L, Rancour P, Robinson M, Neel-Wilson T, Wagner S. A pilot intervention to promote walking and wellness and to improve the health of faculty and staff. $J$ Am Coll Health. 2007;55:219-225.

320 18. Abood DA, Black DR, Feral D. Nutrition education worksite intervention for university staff: application of the health belief model. J Nutr Educ Behav. 2003;35:260-267.

19. Kupchella CE. Colleges and universities should give more broad-based attention to health and wellness - at all levels. J Amer Coll Health. 2009;58:185-186.

20. US Census Bureau. The 2010 Statistical Abstract.

325 http://www.census.gov/compendia/statab/cats/education.html. Accessed February 15, 2010.

21. Sacks G, Swinburn B, Lawrence M. Obesity Policy Action framework and analysis grids for a comprehensive policy approach to reducing obesity. Obesity Rev. 2009;10:76-86.

22. McLeroy KR, Bibeau D, Steckler A, Glanz, K. An ecological perspective on health promotion programs. Health Educ Behav. 1988;15:351-377. 
23. Centers for Disease Control and Prevention. Overweight and obesity. http://www.cdc.gov/obesity/defining.html. Accessed January 15, 2010.

24. Buijsse B, Feskens EJ, Schulze MB, et al. Fruit and vegetable intakes and subsequent changes in body weight in European populations: results from the project on Diet, Obesity, and Genes (DiOGenes). Am J Clin Nutr. 2009;90:202-209.

335 25. US Department of Agriculture. Steps to a Healthier You. www.mypyramid.gov. Accessed January 15, 2010.

26. Flegal KM, Carroll MD, Ogden CL, et al. Prevalence and trends in obesity among US adults, 1999-2008. JAMA. 2010;303:235-241.

27. Centers for Disease Control and Prevention. Healthier Worksite Initiative.

$340 \mathrm{http}: / /$ www.cdc.gov/nccdphp/dnpao/hwi/toolkits/gardenmarket/index.htm. Accessed February 15, 2010.

28. Shive SE, Morris MN. Evaluation of the Energize Your Life! social marketing campaign pilot study to increase fruit intake among community college students. $J$ Am Coll Health. 2006;55:33-39.

345 29. Chu YH, Frongillo EA, Jones SJ, Kaye GL. Improving patrons' meal selections through the use of point-of-selection nutrition labels. Am J Public Health. 2009;99:2001-2005.

30. Freedman MR, Connors R. Point-of-purchase nutrition information influences foodpurchasing behaviors of college students: a pilot study. J Am Diet Assoc. 2010;110:(in press). 